\title{
The Structural Relationship between Service Quality and Sustainable Use Intention of Voice Search Technology in Korea
}

\author{
Jaepil Yoo $\mathbb{C}$
}

Citation: Yoo, J. The Structural Relationship between Service Quality and Sustainable Use Intention of Voice Search Technology in Korea. Sustainability 2021, 13, 14026. https:/ / doi.org/10.3390/su132414026

Academic Editors: Amjad Ali, Farman Ali, Jin-Ghoo Choi and Muhammad Shafiq

Received: 23 November 2021 Accepted: 17 December 2021 Published: 19 December 2021

Publisher's Note: MDPI stays neutral with regard to jurisdictional claims in published maps and institutional affiliations.

Copyright: (C) 2021 by the author. Licensee MDPI, Basel, Switzerland. This article is an open access article distributed under the terms and conditions of the Creative Commons Attribution (CC BY) license (https:// creativecommons.org/licenses/by/ $4.0 /)$.
Department of Management Engineering, Sangmyung University, Seoul 03016, Korea; bond1919@naver.com

\begin{abstract}
Voice search based on artificial intelligence is the fastest means of searching for information and can be easily used in a very familiar way by ordinary users without separate education or learning. Voice bot's voice search can interact on the same level as face-to-face communication and provide customized services optimized for users. It is most important for these new technologies to develop from a non-face-to-face social structure caused by COVID-19 to a long-term sustainable technology rather than short-term development. Therefore, the purpose of this study is to empirically verify the structural relationship between the quality, interactivity, and consumers' sustainable use intentions for voice search services called 'voice bots' in Korea, an advanced country of computer science and technology. A survey was conducted on Korean consumers aged 20 or older who use voice search services, and the following main results were derived. First, the playfulness, certainty, and empathy of the 'voice bot' have a positive effect on the interactivity with the 'voice

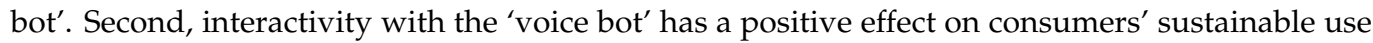
intention. Third, the playfulness and certainty of 'voice bot' have a positive effect on consumers' sustainable use intention. Fourth, the playfulness, certainty, and empathy of the 'voice bot' have a positive effect on consumers' sustainable use intention through interactivity with the 'voice bot'. This study is meaningful in that it empirically identified the importance of interactivity by deriving the service quality factors required for sustainable use of voice search services, one of the new innovative technologies.
\end{abstract}

Keywords: voice search service; voice bot; voice big data; service quality; sustainable interaction; sustainable technological innovation; non-face-to-face service

\section{Introduction}

Recently, as the artificial intelligence (AI)-based voice recognition robot business has been selected as a future growth industry, it is rapidly growing worldwide. In addition, devices that apply artificial intelligence to apply voice assistant functions suitable for users are being developed, and the voice recognition industry requires continuous development because such machines become smarter as users continue to use them. Figure 1 shows a recent survey of 3500 people in Deloitte on the purpose of using the voice recognition service. From this, it can be seen that the frequency of simple voice inquiry services is still high. In the era of the fourth industrial revolution, robot business based on artificial intelligence and voice recognition as such has become a core business strategy of companies centering on IT, and domestic and foreign portal companies have been launching artificial intelligence and voice recognition-based search services [1]. Table 1 explains representative voice recognition devices, and voice recognition systems are applied not only in these representative companies but also in various places such as restaurants, department stores, and bookstores. Artificial intelligence and voice recognition-based search services have expanded the search paradigm using unstructured data such as images and voices, and are already being applied in various fields in South Korea. The voice search market based on voice recognition is satisfying various needs of consumers. Among them, the use of product search and order history tracking through voice search is continuously increasing 
as it has been providing new experiences to users. According to a survey of about 1000 U.S. consumers conducted by Adobe in January 2019, about 36\% of the respondents said they had voice recognition speakers, which does not guarantee sustainable use from a consumer perspective [2]. In other words, it is true that the suggestion of voice recognition services is increasing, but at the same time, analysis of user aspects is very important. Considering this market atmosphere, global companies such as Amazon, Google, Apple, and Samsung Electronics are competing fiercely to develop voice recognition virtual assistant systems and gain market dominance. In 2014, Amazon launched the world's first voice recognition artificial intelligence speaker, Echo, and Google launched Google Home. Meanwhile, in South Korea, KT and SKT are showing advanced technologies in this field. SKT launched the artificial intelligence speaker Nugu for the first time in South Korea in 2016, and KT launched the GiGA Genie in 2017 to provide the world's first IPTV-linked personal assistant function. In 2018, GiGA Genie 2, which is smaller, has improved performance compared to existing devices, and provides an Android-based voice recognition service that was launched [3].
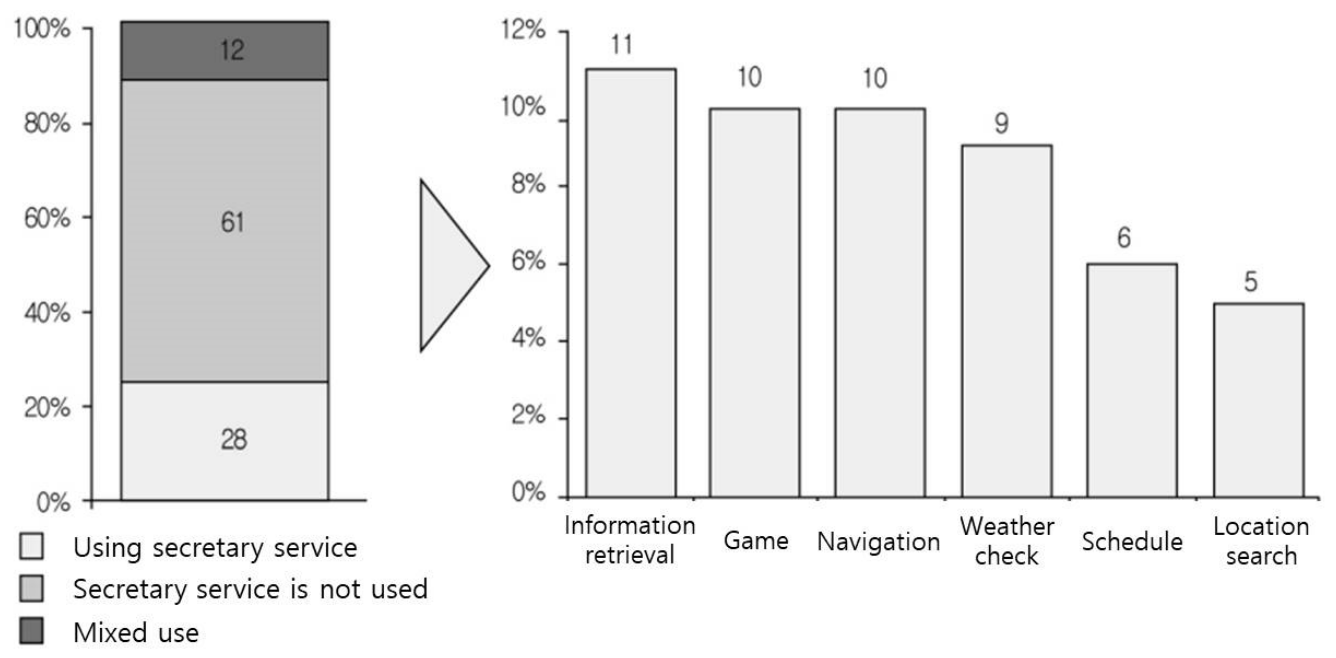

Figure 1. The main purpose of use of the voice recognition assistant service.

Table 1. Voice recognition interactive agent.

Division Characteristics (Release Year)
Apple Siri
LG Q Voice
It was first installed on a smartphone and later applied to a smart TV (2012)
It has the advantage of being able to apply the services of third-party
companies (2014)


Table 1. Cont.

\begin{tabular}{|c|c|c|}
\hline Division & Device & Characteristics (Release Year) \\
\hline MS Cortana & & It started as a voice AI assistant service for PC (2015) \\
\hline Google Assistant & $\begin{array}{l}\text { ogle: } \\
\text { stant Tricks }\end{array}$ & $\begin{array}{l}\text { By securing vast amounts of user data, excellent response services are possible } \\
\text { compared to competitors (2016) }\end{array}$ \\
\hline Samsung Bixby & & $\begin{array}{l}\text { It is based on big data and deep learning and is applicable to all machines of } \\
\text { Samsung Electronics (2017) }\end{array}$ \\
\hline Baidu Duer & & $\begin{array}{l}\text { It is a machine that combines artificial intelligence-based voice recognition and } \\
\text { search technology, and shows an accuracy of about } 98 \% \text { or more (2017) }\end{array}$ \\
\hline
\end{tabular}

There is a prospect that $50 \%$ of Internet searches will be done by voice searches after 2020 [4]. Important reasons why users switch from the existing search methods to voice search are the increased interrelationship with humans as well as technical functions [5]. Another survey found that young people in their 20s had a high utilization rate of speech recognition services [6]. In addition, it is predicted that 30\% of Internet searches will be carried out by pure voice searches without screens in 2020 [7]. Important reasons for this generalization of voice search and the transition from existing search methods to voice search include not only the technical functions and convenience that make voice searches feel like conversations with humans, but also high interrelationships with humans [8]. Meanwhile, the largest characteristic and advantage of information providing service based on artificial intelligence and voice recognition is that it enables interactive communication between the information service providers and consumers. Accordingly, recent studies have verified that these personalized information services increase the interactivity between customers and companies to ultimately increase company loyalty and sustainable usage [9].

Sustainable usage intention can also be defined as the possibility for consumers to use a service repeatedly later [10]. Sustainable usage intention indicates the user's loyalty to the provider of the service used by the user and means the degree to which the user intends to continue to use a certain service after using the service [11]. Sustainable usage intention is an important factor that is generated from the consumers' experience and can lead to long-term relationships with consumers [12] and means consumers' intention to use products or services repeatedly or for a long time [13].

According to a study conducted by Bloemer and Kasper [14], the concept termed sustainable usage is a prerequisite for determining purchase behaviors and is defined as an important indicator for predicting future behaviors of consumers because it is a consumer's disposition expressed according to preference or intention. The decision on the sustainable usage intention for services tends to depend more on past experiences and emotional aspects, and sustainable usage intention is used as an important indicator in evaluating whether the customer will continue the relationship. Recent studies in the fields of marketing and management information argue that the success of a company comes from consumers' continuous use of the company's product or service, not the initial use of the product or service [15]. In order for a service company to secure a sustainable competitive advantage, it should focus on not only securing new customers but also retaining the secured customers, and should perceive that the profits obtained owing to 
customers' sustained uses are larger than the additional profits obtained from the creation of new customers [16].

As reviewed thus far, despite that the quality of information services and interactivity provided in the field of information services are important prerequisites, empirical studies that considered such prerequisites complexly and linked them with consumers' sustainable usage intention are quite insufficient. Therefore, this study explores concepts related to the quality of voice search voice bots perceived by consumers, together with their interactivity and sustainable usage intention, and verifies the final effects of the perceived quality on consumers' sustainable usage intention through interaction.

As the use of voice recognition services increases, many companies are investing in technology development. In order to develop into a sustainable service industry in this situation, an analysis of consumer perception should be conducted at the same time. Therefore, this study aims to verify the influencing relationships among the perceived quality of voice search voice bots, interactivity, and consumers' sustainable usage intention and the mediating effects of interactivity on the relationship between the perceived quality of voice search voice bots and consumers' sustainable usage intention.

\section{Theoretical Background}

\subsection{Perceived Quality}

Perceived quality is the perception or evaluation of certain products felt by consumers according to their comprehensive experiences. It is defined diversely, however; the most commonly accepted definition is that it is the consumers' overall judgment of the excellence or superiority of the relevant products rather than actual quality of the products [17]. In general, since consumers tend to subjectively judge and evaluate when they evaluate products, perceived quality may act more importantly than objective quality [18], and therefore perceived quality is an important variable that determines purchase behavior or purchase intentions [19]. In other words, cognitive quality is of paramount importance to establishing a sustainable industry [20].

Concerning the understanding and measurement of service quality, measuring service quality is not easy because it is an abstract area with no form, but the most appropriate method is to check the level of perception of consumers who firsthand experience the service [21]. That is, consumers have expectation of the level of desirable norm about the relevant service before consuming the service, and how much the quality was actually provided and appropriated is measured through consumer perception of the service quality after consumption. Therefore, finally comparing the expectation and the result was considered to be a method of measuring service quality. In order to measure the service quality, Parasuraman et al. [21] used the SERVQUAL model representing five factors: reliability, assurance, tangibles, empathy, and responsiveness [22]. To review the five scales of service quality perceived by customers appearing in the SERVQUAL model, tangibles mean physical service facilities, equipment, responding personnel, and means of communication; reliability means the ability to make others trust the promised service and provide it accurately; responsiveness means immediate provision of service and the degree to which consumers are helped when they requested; assurance means the ability to give knowledge, confidence, and trust; and empathy means the expression of individual interest and affection to the customer. These five scales presented in the SERVQUAL model have been applied as they are in the field of evaluation. In some cases, depending on business characteristics, the scales have been applied in various forms, such as selective or additional scales presented by researchers. This study intended to measure perceived quality focusing on factors that are highly influential among the five service quality measurement factors of the SERVQUAL model.

In particular, this study adopts empathy and assurance, which were shown to be the most influential on consumer attitudes in the study findings of Kwak and Won [23], first as major measurement variables because empathy and assurance were judged to be variables that can be applied and focused on the information search service quality 
of voice bots in that the foregoing study is a service quality study conducted relatively recently in South Korea. In addition, this study uses playfulness as an additional perceived quality measurement variable, taking notice of the fact that in a study on mobile shopping conducted by Hwang and $\mathrm{Na}$ [9], playfulness related to pleasure and interest in information use, which appeared as an important perceived quality measurement variable, and was determined to be an important factor affecting consumer satisfaction and loyalty.

\subsection{Interactivity}

Interactivity has become a concept used in the scope expanded not only to the relationship between humans but also to the relationship between humans and mechanical media [24]. In other words, the concept termed interactivity, which was considered as only human-to-human communication in the past, is now expanded to include not only interpersonal communication but also communication between smart devices and humans in the new area of ICT [25]. Lee [26] divided the constituent factors of interactivity into control, interactive communication, and responsiveness, and defined control as 'a voluntary and effective action that immediately affects the consumer's experience, and consumers' ability to select contents on their own'; interactive communication as 'the possibility of mutual communication on the Internet, mutual exchanges of opinions between businesses and consumers or between consumers'; and responsiveness as 'the operation of a computer at a speed not disturbing the consumers, i.e., system reaction time and timely reaction rate'.

Lee [26] defined interactivity as the degree to which information search and access is under the control of the end user centering on users' mutual communication, and further, the service-providing system can communicate with individuals and many users through communication equipment as a sender and receiver. Broekhuizen and Hoffmann [27] classified the constituent factors of perceived online interactivity into four factors: interactive communication, user controllability, responsiveness, and multimedia use and execution. These authors defined interactive communication as 'mutual conversion, or user's ability to provide feedback or interact with other users'; user controllability as 'the level of control perceived by the user in computerized interactivity'; responsiveness as 'the rate of reaction in an interface and the degree of correspondence between responses and responsive information'; and multimedia use and execution as 'the degree of diversity of multimedia and the degree of satisfying user needs'.

Therefore, in this study, interactivity with the voice bots is the structural and experiential action for the voice bot and the user to directly communicate with each other, which ultimately can be defined as the action through which the usefulness and convenience of voice bots are perceived highly [28].

\subsection{Sustainable Use Intention}

Sustainable use intention can be defined as the form of repeatedly using a certain product or service, which includes the concept of continuing to use the target product or service currently used, or suggesting and recommending it to others [29]. The reason why sustainable use intention is important is that most of the profits of product and service providers are generated by customers who trade on a long-term and regular basis. Therefore, sustainable use intention can be considered as a factor that has crucially important effects on innovative product and service firms. Bhattacherjee [11] defined sustainable use intention as the intention of consumers to continuously use certain target products or services, and argued that in order to achieve success with an innovative product or service, consumers should use the product or service continuously rather than using it for the first time. In particular, the development of sustainable service technology is essential because speech recognition robots, a crucial phrase in this study, can be a very useful technology for the disabled without hands or feet. In addition, Bhattacherjee [11] explained that introductory success of an IT information system is an important first step, but the sustainable maintenance of the information system and attaining the ultimate goal 
depend on the continuous use of new products or services rather than the introduction in the first step.

Fan et al. [30] explained that sustainable use intention, which is used interchangeably with several other terms, such as intention to continue and intention to use after acceptance, appears in the initial decision of purchase and acceptance, is positively or negatively affected by initial (product or service) use experience, and is similar to consumers' repurchase decisions that lead to the next stage from initial decisions. Lee and Koo [31] stated that IT service firms should secure new potential customers while maintaining existing customers and forming positive relationships with customers. Since IT services are transacted for the characteristics of the goods of knowledge information so that the service quality cannot be easily evaluated without experiencing, customers tend to form a relationship and maintain that relationship continuously, rather than looking for a new service provider. Meanwhile, although reuse intention is an important factor that determines business failure and success, in the IT service industry it is difficult to maintain loyal customers with a tendency to continuously use the services because it is very easy to enter, access, and leave information services. Therefore, it is necessary to determine the factors that affect consumers' sustainable use intention.

\section{Study Design}

\subsection{Study Model and Hypotheses \\ 3.1.1. Study Model}

In this study, the perceived quality of IT company voice bots was designed as the independent variable, and the sustainable use intention of customers was designed as the dependent variable. In addition, to investigate mediating effects on the causal relationship between the variables, interactivity with voice bots was input as a mediator variable. The study model is as follows. We set the characteristics of unmanned order payment service innovation technology as an independent variable, and set resistance and acceptance intent for unmanned order payment service as a dependent variable. The characteristics of innovative technology for unmanned order payment services consisted of a total of three factors: usability, ease of use, and risk that users perceive for unmanned order payment services. It consisted of a single factor for users' resistance to and acceptance of innovative technologies in unmanned order payment services. Figure 2 schematically shows the contents described above.

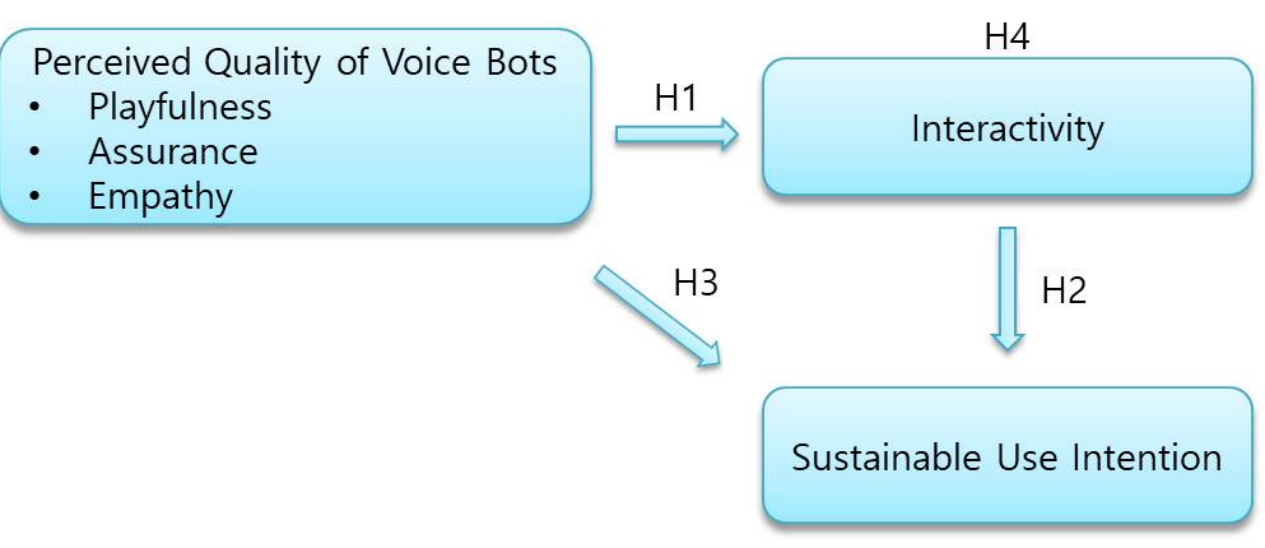

Figure 2. Research model.

\subsubsection{Research Hypotheses}

Based on the model in this study, the following hypotheses were derived. 
Hypothesis 1 (H1). The perceived quality of voice bots has a positive (+) effect on the interactivity with the voice bots.

Hypothesis 1 (H1a). The playfulness of voice bots has a positive (+) effect on the interactivity with the voice bots.

Hypothesis 1 (H1b). The assurance of voice bots has a positive (+) effect on the interactivity with the voice bots.

Hypothesis 1 (H1c). The empathy of voice bots has a positive (+) effect on the interactivity with the voice bots.

Concerning interactivity, Lee et al. [32] reported that interactive communication through which consumers and companies exchange information is possible, and that consumers tend to evaluate sites with high interactivity more favorably and visit such sites more often than sites with low interactivity. No and Kim [33] stated that users perceive that they have a higher degree of control over smart devices and more positively evaluate smart devices when there is more interactivity. Hong et al. [34] examined the effects of the level of chatbot conversational interactivity on system reliability and continuous use intention and reported that according to the results, the greater the interactivity, the greater the reliability and sustainable use intention. It was demonstrated that interactivity has direct and indirect positive effects on users' attitudes and sustainable use intention. On the basis of the previous research, the hypothesis was written as follows.

Hypothesis 2 (H2). Interactivity with voice bots has positive (+) effects on sustainable use intention.

Aaker [35] argued that perceived quality 'directly affects purchase decision and brand loyalty', and said that, in particular, 'perceived quality acts as a decisive factor in purchasing decision when the purchaser's motivation is low'. Jacoby and Kyner [36] emphasized the important role of perceived quality on purchase decision and brand loyalty and stated that perceived quality is a core concept of marketing because it is related to customer attachment to or favorable attitude toward a certain brand, brand preference, or consistent preference tendency shown in purchase. As such, perceived quality is a very important factor in the field of marketing and has a high correlation with users' overall satisfaction and sustainable use intention. That is, after judging the service value expressed as costs versus benefits, consumers experience perceived quality and satisfaction and the experience affect their purchase intention [37]. On the basis of previous research, the hypothesis was written as follows.

Hypothesis 3 (H3). The perceived quality of voice bots has a positive (+) effect on sustainable use intention.

Hypothesis 3 (H3a). The playfulness of voice bots has a positive (+) effect on sustainable use intention.

Hypothesis $3 \mathbf{~ ( H 3 b ) . ~ T h e ~ a s s u r a n c e ~ o f ~ v o i c e ~ b o t s ~ h a s ~ a ~ p o s i t i v e ~ ( + ) ~ e f f e c t ~ o n ~ s u s t a i n a b l e ~}$ use intention.

Hypothesis 3 (H3c). The empathy of voice bots has a positive (+) effect on sustainable use intention.

Hypothesis 4 (H4). Interactivity has mediating effects on the relationship between the perceived quality of voice bots and the sustainable use intention of consumers. 
Hypothesis 4 (H4a). The playfulness of voice bots has a positive (+) effect on sustainable use intention.

Hypothesis $4 \mathbf{( H 4 b )}$. The assurance of voice bots has a positive (+) effect on sustainable use intention.

Hypothesis 4 (H4c). The empathy of voice bots has a positive (+) effect on sustainable use intention.

\subsection{Operational Definition of Variables}

\subsubsection{Perceived Quality of Voice Bots}

In this study, the perceived quality of voice bots was constructed with three subfactors perceived by users, which are playfulness, assurance, and empathy, based on studies conducted by Venkatesh et al. [38]. Among the subfactor of perceived quality, first, playfulness was defined as 'the degree to which pleasure or interest is felt as the emotion obtained from using the voice bots'. Second, assurance was defined as 'the degree of accuracy and confidence of the information provided when using voice bots'. Third, empathy was defined as 'the degree to which voice bots try to understand and know the users' interests and needs when users use voice bots'. All items were measured with a Likert 5-point scale; higher total scores mean higher quality of voice bots perceived by consumers.

\subsubsection{Interactivity with Voice Bots}

In this study, interactivity with voice bots was constructed by making it into a single factor based on a study conducted by Dautenhahn et al. [39], extending the concept of interactivity between humans to interactivity between humans and agents, and defined interactivity as robots' experiential learning of the environment and people on its own. All items were measured with a Likert 5-point scale; higher total scores mean higher levels of interactivity with voice bots.

\subsubsection{Sustainable Use Intention}

In this study, sustainable use intention was constructed by making it into a single factor based on studies conducted Cho and $\operatorname{Im}$ [40]. The sustainable use intention for voice bots was defined as 'voice bot service consumers' behavior intention to continuously use voice bots'. All items were measured with a Likert 5-point scale; higher total scores mean higher intentions to continue using the voice search voice bot service.

\section{Study Results}

\subsection{Demographic Characteristics of Survey Subjects}

The demographic characteristics of the voice bot users who were the subjects of this study are shown in Table 2. As for gender, the subjects consisted of 161 males (59.4\%) and 110 females $(40.6 \%)$, and as for age groups, the subjects consisted of 75 persons in their $20 \mathrm{~s}(27.7 \%), 148$ in their $30 \mathrm{~s}(54.6 \%), 20$ in their $40 \mathrm{~s}(7.4 \%)$, and $28(10.3 \%)$ in their $50 \mathrm{~s}$ or older age groups; thus, those in the age group of 30 s accounted for the majority. As for occupation, the number of office workers including professionals was the largest at $197(72.7 \%)$, followed by that of students at $38(14.0 \%)$, self-employed/business-employed at $31(11.4 \%)$, and homemakers at $5(1.8 \%)$.

Table 2. Demographic characteristics of survey subjects.

\begin{tabular}{ccccc}
\hline \multirow{2}{*}{ Gender } & \multicolumn{2}{c}{ Division } & N & \% \\
\cline { 2 - 5 } & & Male & 161 & 59.4 \\
\cline { 2 - 5 } & & Female & 110 & 40.6 \\
\hline
\end{tabular}


Table 2. Cont.

\begin{tabular}{|c|c|c|c|}
\hline & Division & $\mathbf{N}$ & $\%$ \\
\hline \multirow{4}{*}{ Age } & $20 \mathrm{~s}$ & 75 & 27.7 \\
\hline & $30 \mathrm{~s}$ & 148 & 54.6 \\
\hline & $40 \mathrm{~s}$ & 20 & 7.4 \\
\hline & 50 s or older & 28 & 10.3 \\
\hline \multirow{4}{*}{ Occupation } & Office workers (including professionals) & 197 & 72.7 \\
\hline & Self-employment/Business-employment & 31 & 11.4 \\
\hline & Student & 38 & 14.0 \\
\hline & Homemakers & 5 & 1.8 \\
\hline \multicolumn{2}{|r|}{ Total } & 271 & 100.0 \\
\hline
\end{tabular}

\subsection{Verification of the Validity and Reliability of Measurement Tools}

\subsubsection{Exploratory Factor Analysis and Reliability Verification}

The individual items for measuring the variables used in this study are based on previous studies, and exploratory factor analysis was conducted to verify the construct validity of the measurement items for the perceived quality, interactivity, and sustainable use intention of the voice bots used in the study. Principal component analyses were conducted by study variable for factor analysis, and the varimax method was used for factor rotation.

The exploratory factor analysis in this study seeked to secure validity by refining the variables based on the following criteria. First, items with a factor loading not exceeding 0.50 and items with factor loadings exceeding 0.50 loaded on two or more factors were removed because they were conceptually unclear, and items loaded with factor items that lacked theoretical justification and were not suitable were removed. Thereafter, Cronbach's $\alpha$ values were calculated to verify reliability, which indicates the internal consistency among the items that constitute the factors extracted through factor analysis. In general, reliability was regarded to be secured in cases where the Cronbach's $\alpha$ value was 0.60 to 0.70 or higher.

First, the results of the exploratory factor analysis and reliability analysis for the items for the measurement of the perceived quality of the voice bots used in this study are shown in Table 3. One empathy measurement item that had a low factor loading or showed high loadings on factors with different study concepts in the results of factor analysis was moved. The Kaiser-Meyer-Olkin (KMO) measure for judgment of the sample fit was shown to be 0.858 , and according to the result of Bartlett's sphericity test for verification of whether the correlation matrix between measurement items for factor analysis is a unit matrix, the correlation was significant with the approximated $\chi^{2}=606.611(\mathrm{df})=15, p<0.001$ ), indicating that the data collected and measurement items were suitable for performing factor analysis. As a result of the factor analysis, three factors were extracted as predicted, and the total variance explanatory power was shown to be $68.104 \%$. Concretely, factor 1 was the factor 'assurance' and the variance explanatory power was $24.285 \%$. Factor 2 was the factor 'playfulness' and the variance explanatory power was $23.661 \%$. Factor 3 was the factor 'empathy' and the variance explanatory power was shown to be $20.159 \%$. Therefore, the construct validity was identified.

KMO measure (Kaiser-Meyer-Olkin) $=0.858$, Bartlett's test of sphericity: approximated $\chi^{2}=606.611(\mathrm{df}=15, p=0.000)$. Next, the reliability of the measurement items constituting the perceived quality factors of the voice bots were tested; according to the results, Cronbach's $\alpha$ values for the factors playfulness, assurance, and empathy were shown to be $0.833,0.818$, and 0.815 , respectively, indicating that the factors consisted of items with internal consistency. Therefore, the reliability was secured. 
Table 3. Factor analysis and verification of the reliability of measurement items for the perceived quality of voice bots.

\begin{tabular}{|c|c|c|c|c|c|}
\hline \multirow{2}{*}{ Factor } & \multirow{2}{*}{ Item } & \multicolumn{3}{|c|}{ Factor Loading } & \multirow{2}{*}{ Cronbach's $\alpha$} \\
\hline & & Factor 1 & Factor 2 & Factor 3 & \\
\hline \multirow{4}{*}{ Playfulness } & I feel pleasure when I use a voice bot (PQ 2) & 0.838 & 0.114 & 0.081 & \multirow{4}{*}{0.833} \\
\hline & $\begin{array}{c}\text { The voice bot service is sufficient to stimulate my } \\
\text { curiosity (PQ 3) }\end{array}$ & 0.822 & 0.144 & 0.096 & \\
\hline & $\begin{array}{l}\text { Using the voice bot is novel and I feel interesting } \\
\qquad \text { (PQ 4) }\end{array}$ & 0.803 & 0.084 & 0.149 & \\
\hline & When I use a voice bot, I feel happy (PQ 1) & 0.750 & 0.058 & 0.067 & \\
\hline \multirow{4}{*}{ Assurance } & Voice bots provide information accurately (PQ 6) & 0.034 & 0.847 & 0.085 & \multirow{4}{*}{0.818} \\
\hline & Voice bots definitely deliver results (PQ 7) & 0.107 & 0.839 & -0.014 & \\
\hline & Voice bots are reliable (PQ 5) & 0.151 & 0.741 & 0.160 & \\
\hline & $\begin{array}{c}\text { Voice bots provide services within the promised } \\
\text { time (PQ 8) }\end{array}$ & 0.107 & 0.734 & 0.200 & \\
\hline \multirow{3}{*}{ Empathy } & Voice bots try to empathize with me (PQ 11) & 0.136 & 0.144 & 0.859 & \multirow{3}{*}{0.815} \\
\hline & $\begin{array}{l}\text { Voice bots try to understand what I am asking for } \\
\qquad(\mathrm{PQ} 10)\end{array}$ & 0.108 & 0.061 & 0.836 & \\
\hline & $\begin{array}{l}\text { The voice bot tries to understand matters of my } \\
\text { interest (PQ 12) }\end{array}$ & 0.095 & 0.158 & 0.816 & \\
\hline & Eigenvalue & 2.671 & 2.603 & 2.217 & \\
\hline & Variance \% & 24.285 & 23.661 & 20.159 & \\
\hline & Cumulative variance $\%$ & 24.285 & 47.945 & 68.104 & \\
\hline
\end{tabular}

Exploratory factor analysis and reliability analysis were conducted with the measurement items for the interactivity with and sustainable use interactivity for voice bots. The results are as shown in Table 4. According to the results of the factor analysis, the KMO measure was 0.864 , and the result of the Bartlett's sphericity test showed an approximated $\chi^{2}=1575.442(\mathrm{df}=28, p<0.001)$, indicating that the data collected and measurement items were suitable for performing factor analysis. Through the factor analysis, two factors were extracted without removal of any item, and the total variance explanatory power was shown to be $71.410 \%$. Factor 1 was 'sustainable use intention' for voice bots and its variance explanation power was shown to be $36.106 \%$. Factor 2 was 'sustainable use intention' for voice bots and its variance explanation power was shown to be $71.4107 \%$. Thereafter, the reliability of the components of interactivity with and sustainable use intention for the voice bots was tested and according to the results, Cronbach's $\alpha$ values 0.802 for sustainable use intention for and interactivity with the voice bots were 0.802 and 0.762 , respectively, indicating that the measurement items consisted of items with internal consistency. Therefore, the reliability was secured.

Table 4. Factor analysis and verification of the reliability of measurement items for interactivity with and sustainable use intention voice bots.

\begin{tabular}{|c|c|c|c|c|}
\hline \multirow{2}{*}{ Factor } & \multirow{2}{*}{ Item } & \multicolumn{2}{|c|}{ Factor Loading } & \multirow{2}{*}{ Cronbach's $\alpha$} \\
\hline & & Factor 1 & Factor 2 & \\
\hline \multirow{3}{*}{$\begin{array}{l}\text { Sustainable use } \\
\text { intention }\end{array}$} & I plan to continue using the voice bots hereafter too (CU 2). & 0.903 & 0.156 & \multirow{3}{*}{0.802} \\
\hline & I hope I can continue using voice bots hereafter too (CU 3). & 0.842 & 0.092 & \\
\hline & I plan to use voice bots frequently hereafter too (CU 1). & 0.706 & 0.418 & \\
\hline
\end{tabular}


Table 4. Cont.

\begin{tabular}{|c|c|c|c|c|}
\hline \multirow{2}{*}{ Factor } & \multirow{2}{*}{ Item } & \multicolumn{2}{|c|}{ Factor Loading } & \multirow{2}{*}{ Cronbach's $\alpha$} \\
\hline & & Factor 1 & Factor 2 & \\
\hline \multirow{3}{*}{ Interactivity } & $\begin{array}{l}\text { I feel that interactive communication with voice bots is being } \\
\text { made (Inter 2). }\end{array}$ & 0.155 & 0.852 & \multirow{3}{*}{0.762} \\
\hline & I feel that I interact with voice bots (Inter 1$)$ & 0.084 & 0.803 & \\
\hline & I think I conversate with voice bots in real time (Inter 3). & 0.337 & 0.736 & \\
\hline & Eigenvalue & 2.166 & 2.118 & \\
\hline & Variance \% & 36.106 & 35.304 & \\
\hline & Cumulative variance $\%$ & 36.106 & 71.410 & \\
\hline
\end{tabular}

KMO measure (Kaiser-Meyer-Olkin) $=0.864$, Bartlett's test of sphericity: approximated $\chi^{2}=1575.442(\mathrm{df}=28, p=0.000)$.

\subsubsection{Confirmatory Factor Analysis}

Confirmatory factor analysis was performed on the measurement model to verify the convergent validity and discriminant validity of study variables such as playfulness, assurance, and empathy, which are perceived quality factors of the voice bot, and interactivity with and sustainable use intention for voice bots. In order to evaluate the goodness-of-fit of a measurement model, it is important to select an appropriate goodness-of-fit index that is not sensitive to the sizes of samples, has interpretation criteria, and considers even the simplicity of models. Therefore, in this study, the goodness-of-fit of models was examined using those goodness-of-fit indices such as $\chi 2$ statistics, SRMR (standardized root mean square residual), TLI (Tucker-Lewis index), CFI (comparative fit index), and RMSEA (root mean square error or approximation) with which the confidence interval is presented. In general, $p>0.05$ is appropriate in the case of $\chi 2$ statistics, but other goodness-of-fit indices are considered first because $\chi 2$ statistics are sensitive to the number of samples. TLIs and CFIs not lower than 0.90 indicate good goodness-of-fit and SRMRs not lower than 0.08 indicate good goodness-of-fit [41]. In the case of RMSEA, with which the confidence interval is presented, 0.05 or lower values indicate excellent goodness-of-fit, 0.08 or lower values indicate good goodness-of-fit, and 0.10 or lower values indicate moderate goodnessof-fit [42]. On reviewing the goodness-of-fit of the measurement models presented in Table 5, $\chi 2=251.824(\mathrm{df}=109, p<0.001)$, SRMR $=0.053, \mathrm{TLI}=0.905, \mathrm{CFI}=0.924$, RMSEA $(90 \% \mathrm{CI})=0.070(0.058 \sim 0.081)$ were found, which indicate relatively good goodness-of-fit. Therefore, the measurement models were shown to be suitable for the data. In addition, the factor loadings of all measurement variables for latent variables such as playfulness, assurance, empathy factor, interactivity with the voice bot, and sustainable use intention, which are perceived quality factors of voice bots, were all statistically significant $(p<0.001)$, and did not show any negative error variance (Heywood case).

Table 5. Results of confirmatory factor analysis.

\begin{tabular}{|c|c|c|c|c|c|c|c|c|c|}
\hline & Division & & $\begin{array}{l}\text { Unstandardized } \\
\text { Factor Loading }\end{array}$ & $\begin{array}{c}\text { Standard } \\
\text { Error }\end{array}$ & $\begin{array}{l}\text { Standardized } \\
\text { Factor Loading }\end{array}$ & $\begin{array}{c}\text { Error } \\
\text { Variance }\end{array}$ & $\mathbf{t}$ & $\begin{array}{l}\text { Construct } \\
\text { Reliability } \\
\text { (CR) }\end{array}$ & $\begin{array}{c}\text { Average } \\
\text { Variance } \\
\text { Extracted } \\
\text { (AVE) }\end{array}$ \\
\hline \multirow{4}{*}{ Playfulness } & $\rightarrow$ & PQ 1 & 1.000 & - & 0.626 & 0.499 & - & \multirow{4}{*}{0.842} & \multirow{4}{*}{0.574} \\
\hline & $\rightarrow$ & PQ 2 & 1.338 & 0.136 & 0.777 & 0.378 & $9.868^{* * *}$ & & \\
\hline & $\rightarrow$ & PQ 3 & 1.416 & 0.140 & 0.811 & 0.336 & $10.105^{* * *}$ & & \\
\hline & $\rightarrow$ & PQ 4 & 1.395 & 0.143 & 0.764 & 0.448 & $9.762^{* * *}$ & & \\
\hline \multirow{4}{*}{ Assurance } & $\rightarrow$ & PQ 5 & 1.000 & - & 0.687 & 0.442 & - & \multirow{4}{*}{0.849} & \multirow{4}{*}{0.585} \\
\hline & $\rightarrow$ & PQ 6 & 1.138 & 0.107 & 0.790 & 0.308 & $10.651^{* * *}$ & & \\
\hline & $\rightarrow$ & PQ 7 & 1.068 & 0.102 & 0.766 & 0.317 & $10.456^{* * *}$ & & \\
\hline & $\rightarrow$ & PQ 8 & 0.979 & 0.103 & 0.676 & 0.450 & $9.493^{* * *}$ & & \\
\hline
\end{tabular}


Table 5. Cont.

\begin{tabular}{|c|c|c|c|c|c|c|c|c|c|}
\hline & Division & & $\begin{array}{l}\text { Unstandardized } \\
\text { Factor Loading }\end{array}$ & $\begin{array}{c}\text { Standard } \\
\text { Error }\end{array}$ & $\begin{array}{l}\text { Standardized } \\
\text { Factor Loading }\end{array}$ & $\begin{array}{c}\text { Error } \\
\text { Variance }\end{array}$ & $\mathbf{t}$ & $\begin{array}{l}\text { Construct } \\
\text { Reliability } \\
\text { (CR) }\end{array}$ & $\begin{array}{c}\text { Average } \\
\text { Variance } \\
\text { Extracted } \\
\text { (AVE) }\end{array}$ \\
\hline \multirow{3}{*}{ Empathy } & $\rightarrow$ & PQ 10 & 1.000 & - & 0.739 & 0.436 & - & \multirow{3}{*}{0.829} & \multirow{3}{*}{0.618} \\
\hline & $\rightarrow$ & PQ 11 & 1.142 & 0.100 & 0.852 & 0.259 & $11.441^{* * *}$ & & \\
\hline & $\rightarrow$ & PQ 12 & 0.955 & 0.088 & 0.730 & 0.420 & $10.841^{* * *}$ & & \\
\hline \multirow{3}{*}{ Interactivity } & $\rightarrow$ & Inter 1 & 1.000 & - & 0.660 & 0.540 & - & \multirow{3}{*}{0.789} & \multirow{3}{*}{0.542} \\
\hline & $\rightarrow$ & Inter 2 & 1.036 & 0.112 & 0.743 & 0.365 & $9.228^{* * *}$ & & \\
\hline & $\rightarrow$ & Inter 3 & 1.161 & 0.125 & 0.759 & 0.414 & $9.305^{* * *}$ & & \\
\hline \multirow{3}{*}{$\begin{array}{l}\text { Sustainable } \\
\text { use }\end{array}$} & $\rightarrow$ & CU 1 & 1.000 & - & 0.734 & 0.366 & - & \multirow{3}{*}{0.844} & \multirow{3}{*}{0.645} \\
\hline & $\rightarrow$ & CU 2 & 1.129 & 0.093 & 0.876 & 0.165 & $12.147^{* * *}$ & & \\
\hline & $\rightarrow$ & CU 3 & 1.081 & 0.099 & 0.718 & 0.471 & $10.925^{* * *}$ & & \\
\hline
\end{tabular}

Next, to examine the convergent validity of latent variables, construct reliability (CR) and average variance extracted (AVE) values were reviewed. First, convergent validity refers to the degree of correlations between one latent variable and two or more measurement items. In general, the standardized factor loading should be significant with a value not lower than 0.50 , and if the concept reliability value of a variable is 0.70 or higher and the average variance extracted value is 0.50 or higher, the variable is considered to have convergent validity.

As shown in Table 5, the standardized factor loadings of the measurement items were all higher than 0.50 , and in the case of construct reliability (CR), all the values for playfulness (0.842), assurance (0.849), and empathy (0.829), which are the factors of perceived quality of voice bots, and latent variables such as interactivity with voice bots $(0.789)$ and sustainable use intention (0.844) were shown be at least 0.70 . All the average variance extracted (AVE) values for playfulness (0.574), assurance (0.585), and empathy (0.618), which are the factors of perceived quality of voice bots, and latent variables such as interactivity with voice (0.542) and sustainable use intention (0.645), were shown to be at least 0.50 , so that the convergent validity was confirmed.

Finally, discriminant validity between latent variables was examined. Discriminant validity indicates how much one latent variable is actually different from other latent variables. The most conservative evaluation method concerns two latent variables having discriminant validity in cases where each of the average variance extracted values of two latent variables is larger than the square of the correlation coefficient of the two latent variables. The discriminant validity was checked by comparing the values of the square of the correlation coefficients and the average variance extracted values presented in Table 6 and according to the results, the squared value $(0.213)$ of the correlation coefficient $(0.461)$ between the playfulness of the voice bot and the latent variables of interactivity with voice bots showing the highest correlation were lower than the average variance extracted value so that the discriminant validity between the latent variables was secured.

When the correlations between the study variables were examined, it was found that playfulness, assurance, and empathy, which are the factors of the perceived quality of voice bots, had significant positive $(+)$ correlations with interactivity with voice bots and sustainable use intention, and that interactivity with the voice bot had a significant positive correlation with sustainable use intention. 
Table 6. Correlations between study variables.

\begin{tabular}{|c|c|c|c|c|c|}
\hline \multirow{2}{*}{ Division } & \multicolumn{3}{|c|}{ Perceived Quality } & \multirow{2}{*}{ Interactivity } & \multirow{2}{*}{$\begin{array}{c}\text { Sustainable } \\
\text { Use } \\
\text { Intention }\end{array}$} \\
\hline & Playfulness & Assurance & Empathy & & \\
\hline Playfulness & 0.574 & & & & \\
\hline Assurance & $\begin{array}{c}0.302 * * * \\
(0.091)\end{array}$ & 0.585 & & & \\
\hline Empathy & $\begin{array}{l}0.321 * * * \\
(0.103)\end{array}$ & $\begin{array}{c}0.327 * * * \\
(0.107)\end{array}$ & 0.618 & & \\
\hline Interactivity & $\begin{array}{c}0.461^{* * *} \\
(0.213)\end{array}$ & $\begin{array}{c}0.347^{* * *} \\
(0.120)\end{array}$ & $\begin{array}{c}0.405^{* * *} \\
(0.164)\end{array}$ & 0.542 & \\
\hline $\begin{array}{l}\text { Sustainable } \\
\text { use intention }\end{array}$ & $\begin{array}{c}0.455^{* * *} \\
(0.207)\end{array}$ & $\begin{array}{c}0.429 * * * \\
(0.184)\end{array}$ & $\begin{array}{c}0.309 * * * \\
(0.095)\end{array}$ & $\begin{array}{l}0.558^{* * *} \\
(0.311)\end{array}$ & 0.645 \\
\hline
\end{tabular}

\subsection{Study Hypothesis Testing}

Structural equation model analysis was performed using AMOS 26.0 to test the study hypotheses to examine the structural causal relationships among playfulness, assurance, and empathy, which are the factors of the perceived quality of voice bots, interactivity with voice bots, and sustainable use intention, and the maximum likelihood (ML) method was used for parameter estimation. First, on reviewing the goodness-of-fit of the study models presented in Table 7, $\chi 2=251.824(\mathrm{df}=109, p<0.001), \mathrm{SRMR}=0.053, \mathrm{TLI}=0.905$, $\mathrm{CFI}=0.924$, RMSEA $(90 \% \mathrm{CI})=0.070(0.058 \sim 0.081)$, etc., were shown to indicate good goodness-of-fit. Therefore, the models were found to have no difficulty in accommodating the study results.

Table 7. Goodness-of-fit of study models.

\begin{tabular}{ccccccc}
\hline$\chi^{2}$ & $d f$ & $p$ & SRMR & TLI & CFI & RMSEA (90\% CI) \\
\hline 251.824 & 109 & 0.000 & 0.053 & 0.905 & 0.924 & $0.070(0.058-0.081)$ \\
\hline
\end{tabular}

The results of tests of the study hypotheses established to examine the causal relationships among playfulness, assurance, and empathy, which are the factors of the perceived quality of voice bots, and the latent variables, interactivity with voice bots and sustainable use intention, are shown in Figure 3 and Table 8.

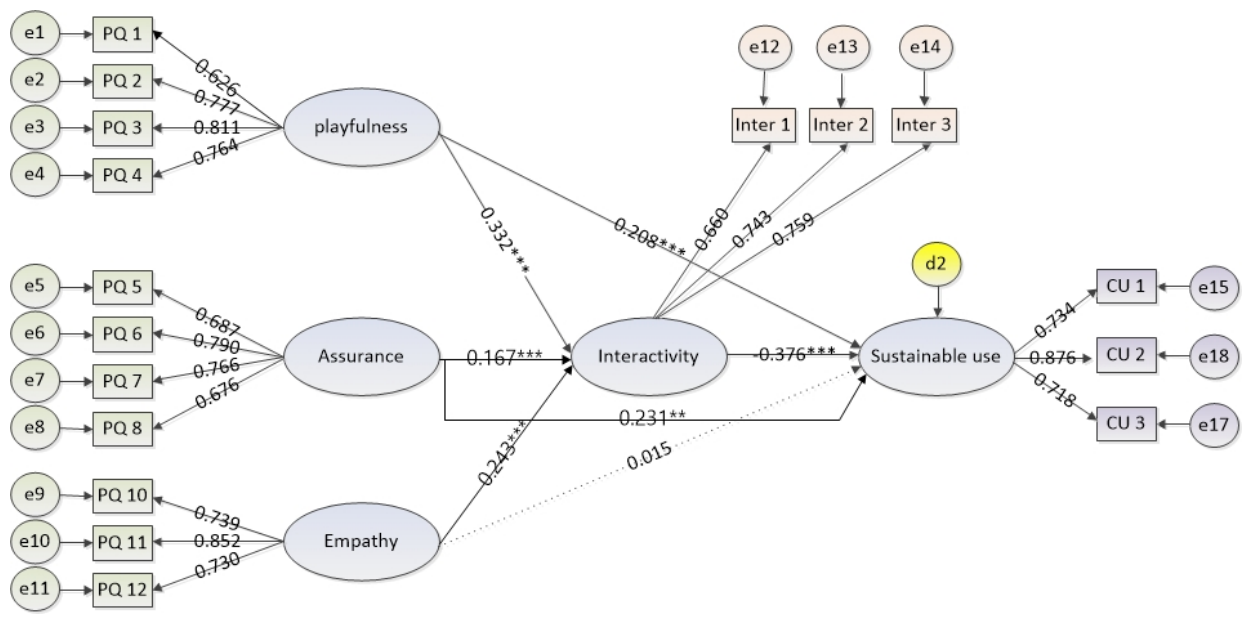

Figure 3. Results of tests of study models. ${ }^{* *} p<0.01,{ }^{* * *} p<0.001$ (standardized path coefficient). 
Table 8. Test results of study hypotheses.

\begin{tabular}{|c|c|c|c|c|c|}
\hline Path & $\begin{array}{l}\text { Unstandardized } \\
\text { Path Coefficient }\end{array}$ & Standard Error & $\begin{array}{c}\text { Standardized } \\
\text { Path Coefficient }\end{array}$ & $\mathrm{t}(C . R)$ & $p$ \\
\hline $\begin{aligned} & \text { Playfulness } \\
\rightarrow & \text { Interactivity }\end{aligned}$ & 0.378 & 0.094 & 0.332 & 4.022 & 0.000 \\
\hline $\begin{aligned} & \text { Assurance } \\
& \rightarrow \text { Interactivity } \\
&\end{aligned}$ & 0.172 & 0.079 & 0.167 & 2.167 & 0.030 \\
\hline $\begin{aligned} & \text { Empathy } \\
& \rightarrow \text { Interactivity } \\
&\end{aligned}$ & 0.217 & 0.071 & 0.243 & 3.076 & 0.002 \\
\hline $\begin{array}{c}\text { Interactivity } \\
\rightarrow \text { Sustainable use intention }\end{array}$ & 0.381 & 0.091 & 0.376 & 4.202 & 0.000 \\
\hline $\begin{array}{c}\text { Playfulness } \\
\rightarrow \text { Sustainable use intention }\end{array}$ & 0.239 & 0.088 & 0.208 & 2.726 & 0.006 \\
\hline $\begin{array}{c}\text { Assurance } \\
\rightarrow \text { Sustainable use intention }\end{array}$ & 0.24 & 0.075 & 0.231 & 3.186 & 0.001 \\
\hline $\begin{array}{l}\text { Empathy } \rightarrow \\
\text { Sustainable use intention }\end{array}$ & 0.013 & 0.065 & 0.015 & 0.206 & 0.837 \\
\hline
\end{tabular}

On reviewing the test results of study hypothesis 1 , which predicted that the perceived quality of voice bots would affect interactivity with voice bots, among the factors of the perceived quality of voice bots, of playfulness (standardized path coefficient $=0.332$, $\mathrm{t}=4.022, p<0.001$ ), assurance (standardized path coefficient $=0.167, \mathrm{t}=2.167, p<0.05$ ), and empathy (standardized path coefficient $=0.243, \mathrm{t}=3.076, p<0.01$ ) were found to have significant positive $(+)$ effects on the interactivity with voice bots. These results mean that the higher the voice bot users perceive the playfulness, assurance, and empathy of the voice bots, the higher the interactivity with voice bots. Therefore, it can be seen that playfulness, assurance, and empathy, which are factors of the perceived quality of voice bots, are major predictors that positively affect interactivity with voice bots. Therefore, study hypotheses 1-1, 1-2, and 1-3 were all adopted.

Next, on reviewing the test results of study hypothesis 2, which predicted that interactivity with voice bots would affect sustainable use intention, interactivity with voice bots was found to have a significant positive effect on sustainable use intention (standardized path coefficient $=0.376, \mathrm{t}=4.202, p<0.001$ ), indicating that the better the consumers interact with voice bots, the higher the sustainable use intention for voice bots. Therefore, study hypothesis 2 was adopted.

On reviewing the test results of study hypothesis 3 , which predicted that the factor of the perceived quality of voice bots would affect sustainable use intention, the playfulness (standardized path coefficient $=0.208, \mathrm{t}=2.726, p<0.01$ ) and assurance (standardized path coefficient $=0.231, \mathrm{t}=3.186, p<0.01$ ) of voice bots were found to have direct and significant positive effects on sustainable use intention, but the factor empathy was found to have no direct significant effect on sustainable use intention. These results mean that the higher the consumers perceive playfulness and assurance of voice bots, the higher the sustainable use intention of consumers. Therefore, it can be seen among the factors of perceived quality of voice bots, playfulness and assurance have direct positive effects on sustainable use intention. Therefore, study hypotheses 3-1 and 3-2 were adopted, but hypothesis 3-3 was rejected.

Next, in order to test study hypothesis 4 , which predicted that the interactivity with voice bots would have a mediating effects on the relationship between the perceived quality of vice bots and sustainable use intention, bootstrapping was performed on the indirect effect of these paths. Bootstrapping is a method of estimating the distribution of parameters based on sample data without knowing the distribution of the population, in which cases where 0 is not included in the $95 \%$ confidence interval are judged to be significant at the 0.05 level. The results of the test are shown in Table 9. 
Table 9. Verification results of mediating effects on interactivity with voice bots.

\begin{tabular}{|c|c|c|c|c|c|}
\hline \multirow[b]{2}{*}{ Path } & \multicolumn{5}{|c|}{ Indirect Effect (Bootstrap) } \\
\hline & $\begin{array}{l}\text { Unstandardized } \\
\text { Path Coefficient }\end{array}$ & Standard Error & $\begin{array}{l}\text { Standardized } \\
\text { Path Coefficient }\end{array}$ & $95 \%$ CI & $p$ \\
\hline $\begin{array}{l}\text { Playfulness } \rightarrow \text { Interactivity } \\
\rightarrow \text { Sustainable use intention }\end{array}$ & 0.144 & 0.061 & 0.125 & $\begin{array}{l}(0.060- \\
0.309)\end{array}$ & 0.001 \\
\hline $\begin{array}{l}\text { Assurance } \rightarrow \text { Interactivity } \\
\rightarrow \text { Sustainable use intention }\end{array}$ & 0.066 & 0.037 & 0.063 & $\begin{array}{l}(0.011- \\
0.162)\end{array}$ & 0.018 \\
\hline $\begin{array}{l}\text { Empathy } \rightarrow \text { Interactivity } \\
\rightarrow \text { Sustainable use intention }\end{array}$ & 0.083 & 0.043 & 0.092 & $\begin{array}{l}(0.020- \\
0.192)\end{array}$ & 0.009 \\
\hline
\end{tabular}

Bootstrap sampling: 2000 times.

The mediating effects of interactivity with voice bots on the relationship between the perceived quality of voice bots and sustainable use intention of consumers were tested; according to the results, the indirect effect of the paths, voice bots' playfulness $\rightarrow$ interactivity $\rightarrow$ sustainable use intention (nonstandardized path coefficient $=0.144,95 \%$ CI: 0.060 0.309, $p<0.01$ ), assurance $\rightarrow$ interactivity $\rightarrow$ sustainable use intention (nonstandardized path coefficient $=0.066,95 \%$ CI: 0.011 0.162, $p<0.05$ ), and empathy $\rightarrow$ interactivity $\rightarrow$ sustainable use intention (nonstandardized path coefficient $=0.083,95 \%$ CI: 0.020 0.192, $p<0.01$ ) did not include 0 in the $95 \%$ confidence interval, indicating that the indirect effects were significant. Therefore, the mediating effects were verified.

Through these results, it can be seen that playfulness, assurance, and empathy, which are the factors of the perceived quality of voice bots, affect the sustainable use intention through the mediation of interactivity with voice bot. Therefore, study hypotheses 4-1, 4-2, and 4-3 were all adopted.

On synthesizing these results, it was found that among the factors of the perceived quality of voice bots, empathy does not directly affect sustainable use intention, but only affects sustainable use intention through the mediation of interactivity with voice bots, indicating that interactivity with voice bots had complete mediating effects. Playfulness and assurance were found to affect sustainable use intention, not only directly but also through the mediation of interactivity with voice bots, indicating that interactivity with voice bot had partial mediating effects. These test results of study hypotheses are summarized and presented in Table 10.

Table 10. Summary of the results of tests of study hypotheses.

\begin{tabular}{|c|c|c|}
\hline & Hypothesis & $\begin{array}{l}\text { Results of Test of } \\
\text { Hypothesis }\end{array}$ \\
\hline Hypothesis 1 (H1) & $\begin{array}{l}\text { The perceived quality of voice bots has a positive }(+) \text { effect on the } \\
\text { interactivity with the voice bots. }\end{array}$ & Adopted \\
\hline Hypothesis 1 (H1a) & $\begin{array}{l}\text { The playfulness of voice bots has a positive }(+) \text { effect on the interactivity } \\
\text { with the voice bots. }\end{array}$ & Adopted \\
\hline Hypothesis 1 (H1b) & $\begin{array}{l}\text { The assurance of voice bots has a positive (+) effect on the interactivity } \\
\text { with the voice bots. }\end{array}$ & Adopted \\
\hline Hypothesis 1 (H1c) & $\begin{array}{l}\text { The empathy of voice bots has a positive (+) effect on the interactivity } \\
\text { with the voice bots. }\end{array}$ & Adopted \\
\hline Hypothesis 2 (H1) & $\begin{array}{l}\text { Interactivity with voice bots has positive }(+) \text { effects on } \\
\text { sustainable use intention. }\end{array}$ & Adopted \\
\hline Hypothesis 3 (H1) & $\begin{array}{c}\text { The perceived quality of voice bots has a positive }(+) \text { effect on } \\
\text { sustainable use intention. }\end{array}$ & Adopted \\
\hline
\end{tabular}


Table 10. Cont.

\begin{tabular}{lccc}
\hline & Hypothesis & $\begin{array}{c}\text { Results of Test of } \\
\text { Hypothesis }\end{array}$ & Adopted \\
\hline Hypothesis 3 (H1a) & The playfulness of voice bots has a positive (+) effect on \\
sustainable use intention. & The assurance of voice bots has a positive (+) effect on \\
sustainable use intention. & Adopted \\
\hline Hypothesis 3 (H1b) & The empathy of voice bots has a positive (+) effect on sustainable use intention. & Rejected \\
\hline Hypothesis 3 (H1c) & $\begin{array}{c}\text { Interactivity has mediating effects on the relationship between the perceived } \\
\text { quality of voice bots and the sustainable use intention of consumers. }\end{array}$ & Adopted \\
\hline Hypothesis 4 (H1) & $\begin{array}{c}\text { Interactivity has mediating effects on the relationship between the playfulness } \\
\text { of voice bots and the sustainable use intention of consumers. }\end{array}$ & Adopted \\
\hline Hypothesis 4 (H1a) & voice bots and the sustainable use intention of consumers. & Adopted \\
\hline Hypothesis 4 (H1c) & $\begin{array}{c}\text { Interactivity has mediating effects on the relationship between the empathy of } \\
\text { voice bots and the sustainable use intention of consumers. }\end{array}$ & Adopted \\
\hline
\end{tabular}

\section{Discussion}

In this study, the structural relationships among the quality of voice search voice bots perceived by consumers, interactivity, and the sustainable use intention of consumers were empirically verified. The major results of this study are discussed, centering on the results of tests of hypotheses as follows.

First, according to the results of analysis of the effects of the perceived quality of voice bots on interactivity with voice bots, among the factors of the perceived quality of voice bots, playfulness (standardized path coefficient $=0.332, \mathrm{t}=4.022, p<0.001$ ), assurance (standardized path coefficient $=0.167, \mathrm{t}=2.167, p<0.05$ ), and empathy (standardized path coefficient $=0.243, t=3.076, p<0.01)$ had significant positive $(+)$ effects on interactivity with voice bots. These results mean that the higher the voice bot users perceive the playfulness, certainty, and empathy of voice bots, the higher the interactivity with voice bot, indicating that playfulness, assurance, and empathy, which are the factors of the perceived quality of voice bots, are predisposing factors that positively affect the interactivity with voice bots. The results in this study are supported by a study conducted by Kim et al. [43], who reported that pleasure, which is a form of intrinsic motivations formed through the use of UCC, that is, playfulness, had significant effects on interactivity, and the results of a study conducted by Song and Yun [44], who argued that giving emotions or empathy in a conversational environment between agents such as voice bots and users enhances interactivity. In addition, the results of this study are consistent with the results of a study conducted by Lee et al. [45], which presented the results of empirical analysis indicating that assurance has positive effects on interactivity. In particular, given that assurance of voice bots is the degree to which voice bots are equipped with sufficient databases for the service provided, and deliver trust and confidence to users, the results can be explained by suggesting that the assurance perceived in voice bots can be linked to interactivity.

Second, the effects of interactivity with voice bots on sustainable use intention were analyzed; according to the results, interactivity with voice bot had significant positive $(+)$ effects on sustainable use intention (standardized path coefficient $=0.376, t=4.202$, $p<0.001$ ), indicating that the better the consumers interact with voice bots, the higher the sustainable use intention of consumers. These results are in line with the results of a study conducted by Venkatesh [38] indicating that the perceived quality of voice bots has positive effects on interactivity with voice bots, thereby supporting the results of this study. These results can be seen as consistent with the results of research conducted by Lee et al. [45], and in previous studies, intimacy and enjoyment with voice search robots can be strengthened to contribute to sustainability. That is, these results mean that if voice 
bots are perceived to have emotions as with humans by consumers, the familiarity of voice bots are enhanced, leading to higher interactivities between the bots and the consumers, consequently leading to sustainable use.

Third, the effects of the perceived quality of voice bots on sustainable use intention were analyzed; according to the results, the playfulness (standardized path coefficient $=0.208$, $\mathrm{t}=2.726, p<0.01$ ) and assurance (standardized path coefficient $=0.231, \mathrm{t}=3.186, p<0.01$ ) of voice bots had direct significant positive $(+)$ effects on sustainable use intention, but the factor empathy had no direct significant effect on sustainable use intention. These results mean that the higher the consumers perceive the playfulness and assurance of voice bots, the higher the sustainable use intention of consumers. Therefore, it can be seen that among the factors of the perceived quality of voice bots, playfulness and assurance positively also affect sustainable use intention directly. That is, the greater the fun or pleasure felt by using the voice search of voice bots, and the higher the trust and accuracy of information, the higher the intention of consumers to use voice bots. These results can be said to have confirmed once again that perceived quality has been found to be a predisposing factor of consumers' sustainable use intention in many previous studies. These results are also consistent with a study conducted by Chen and Lin [46], which showed that the perceived quality of blog services had positive effects on sustainable use intention, and a study conducted by Turel et al. [47] indicating that the overall perceived value of hedonic digital works such as MP3 has significant effects on the intention for later use. However, among the factors of perceived qualities, empathy did not have any significant effect on sustainable use intention, and this result is contrary to previous studies, which reported that perceived quality affects sustainable use intention. The result of this study, indicating that empathy does not affect sustainable use intention, means that empathy with others does not necessarily affect sustainable use intention. Therefore, when seen from the dimension of marketing, it is judged that it is necessary to develop voice services so that playfulness and assurance that showed significant effects can be perceived highly or makes an effort to improve voice service in such a direction.

Fourth, the mediating effects of interactivity with voice bots on the relationship between the perceived quality of voice bots and sustainable use intention of consumers were analyzed; according to the results, the indirect effect of the paths, voice bots' playfulness $\rightarrow$ interactivity $\rightarrow$ sustainable use intention (nonstandardized path coefficient $=0.144,95 \%$ CI: $0.060 \sim 0.309, p<0.01$ ), assurance $\rightarrow$ interactivity $\rightarrow$ sustainable use intention (nonstandardized path coefficient $=0.066,95 \%$ CI: 0.011 0.162, $p<0.05)$, and empathy $\rightarrow$ interactivity $\rightarrow$ sustainable use intention (nonstandardized path coefficient $=0.083,95 \%$ CI: 0.020 0.192, $p<0.01$ ) were shown to be significant, indicating that the mediating effects were significant. Through these results, it was identified that playfulness, assurance, and empathy, which are the factors of the perceived quality of voice bots, affect sustainable use intention through the mediation of interactivity with voice bots. Previous studies that analyzed the mediating effects of interactivity with voice bots on the relationship between the perceived quality of voice bots and the sustainable use intention of consumers can be hardly found. However, given the studies conducted by Kim [43] and Lee et al. [45], mentioned above, which reported that the perceived quality of voice bots had positive effects on interactivity with voice bots, along with a study conducted by Venkatesh [38], which presented the study finding indicating that interactivity with voice bots had positive effects on sustainable use intention, it can be predicted that the perceived quality of voice bots can positively affect the sustainable use intention of consumers through the mediation of interactivity with voice bots.

Finally, it is hoped that this study will help develop voice search service technology from a sustainable perspective in a non-face-to-face social system in the COVID-19 era.

\section{Conclusions}

As written above, study findings regarding the structural relationships among the quality of voice search voice bots perceived by consumers, interactivity, and the sustainable 
use intention of consumers were discussed. This study is judged to be able to provide many practical and theoretical implications for new marketing techniques of companies that provide voice search services in the era of the fourth industrial revolution, in that it derived the service quality factors for voice search voice bots that are predisposing factors for sustainable use intentions, and went further to empirically identify the importance of interactivity of voice bots in the process. In particular, since this study verified the role of the interactivity with voice bots along with the factors of the perceived quality of voice bots, this study contributes to the development of theories in the fields of marketing and customer management of voice search service providers, presenting implications on how to effectively provide customer services to related companies. Meanwhile, since this study was conducted with 271 Korean adults in their 20s or older who use voice search services, there may be limitations in generalizing the findings of this study as those applicable to all consumers. Therefore, in follow-up studies, it is necessary to present more generalized study findings through more comprehensive research studies, including consumers who use voice search services in other countries in addition to South Korean consumers. In addition, since this study is an experiment to establish opinions on the sustainable development of the voice bot provided, the experiment was conducted only on those who actually used the voice bot. In future research, it is believed that if research is conducted, including those who did not use voice search voice bots and expectations for voice bots, potential customer tendencies can be analyzed.

Funding: This research received no external funding.

Institutional Review Board Statement: Not applicable.

Informed Consent Statement: Not applicable.

Data Availability Statement: Not applicable.

Conflicts of Interest: The author declares no conflict of interest.

\section{References}

1. Hwang, S.H.; Ju, D.Y. Usability Evaluation of Artificial Intelligence Search Services Using the Naver App. Korean Soc. Emot. Sensib. 2019, 22, 49-58. [CrossRef]

2. Manikonda, L.; Deotale, A.; Kambhampati, S. What's up with privacy?: User preferences and privacy concerns in intelligent personal assistants. In Proceedings of the 2018 AAAI/ACM Conference on AI, Ethics, and Society, New Orleans, LA, USA, 2-3 February 2018; pp. 229-235. [CrossRef]

3. Kim, M.; Kim, Y.; Yoon, Y.; Kim, H. Implementation of IoT Smart Blackout Curtain Including Voice Recognition Function. Int. J. Internet Things Appl. 2020, 4, 1-6. [CrossRef]

4. Kim, E.Y. A Study on the Relationship Between Perceived Quality, Perceived Personalization and Consumer Attitude of the Voicebot for Voice Search: Focusing on the Dual Mediation Effect of Perceived Anthropomorphism and Interactivity. Master's Thesis, Hongik University, Seoul, Korea, 2020. [CrossRef]

5. Sung, H.; Jeon, H. Untact: Customer's Acceptance Intention toward Robot Barista in Coffee Shop. Sustainability 2020, $12,8598$. [CrossRef]

6. Sa, N.; Yuan, X. Examining User Perception and Usage of Voice Search. Data Inf. Manag. 2021, 5, 40-47. [CrossRef]

7. Yeon, D.; Park, G.; Kim, H.-W. User Experience Analysis and Management Based on Text Mining: A Smart Speaker Case. Inf. Syst. Rev. 2020, 22, 77-99. [CrossRef]

8. Nahavandi, S. Industry 5.0—A Human-Centric Solution. Sustainability 2019, 11, 4371. [CrossRef]

9. McMillan, S.; Hwang, J.-S. Measures of Perceived Interactivity: An Exploration of the Role of Direction of Communication, User Control, and Time in Shaping Perceptions of Interactivity. J. Advert. 2013, 31, 29-42. [CrossRef]

10. Garbarino, E.; Johnson, M.S. The Different Roles of Satisfaction, Trust, and Commitment in Customer Relationships. J. Mark. 1999, 63, 70-87. [CrossRef]

11. Bhattacherjee, A. An empirical analysis of the antecedents of electronic commerce service continuance. Decis. Support Syst. 2001, 32, 201-214. [CrossRef]

12. Dorsch, M.J.; Grove, S.J.; Darden, W.R. Consumer intentions to use a service category. J. Serv. Mark. 2000, 14, 92-117. [CrossRef]

13. Suh, M.W. A Study on the Sustainability of Wood Product Through Consumer Participatio. Art. Des. 2021, 24, 69-83.

14. Bloemer, J.; Kasper, H.D. The complex relationship between consumer satisfaction and brand loyalty. J. Econ. Psychol. 1995, 16, 311-329. [CrossRef] 
15. Han, S.I.; Chang, S.J. A Study on User Satisfaction and Continuity Usage Intention in the Automotive Industry: Focusing on the Expectation Confirmation Model. Asia-Pac. J. Bus. Ventur. Entrep. 2021, 16, 189-203. [CrossRef]

16. Na, Y.K.; Kang, S.; Jeong, H.Y. The Effect of Market Orientation on Performance of Sharing Economy Business: Focusing on Marketing Innovation and Sustainable Competitive Advantage. Sustainability 2019, 11, 729. [CrossRef]

17. Parasuraman, A.; Zeithaml, V.A.; Berry, L. SERVQUAL: A multiple-item scale for measuring consumer perceptions of service quality. J. Ret. 1988, 64, 12-40.

18. Kang, C.M.; Lee, G.C. Analysis of Effects of Rational and Emotional Advertising Appeals on Products from a View of Psychological Distance: Focusing on the Eye-Tracking Method. J. Dig. Con. 2019, 17, 97-104. [CrossRef]

19. Szybillo, G.J.; Jacoby, J. Intrinsic versus extrinsic cues as determinants of perceived product quality. J. Appl. Psychol. 1974, 59, 74-78. [CrossRef]

20. Beneke, J.; Flynn, R.; Greig, T.; Mukaiwa, M. The influence of perceived product quality, relative price and risk on customer value and willingness to buy: A study of private label merchandise. J. Prod. Brand Manag. 2013, 22, 218-228. [CrossRef]

21. Zeithaml, V.A.; Berry, L.L.; Parasuraman, A. Communication and Control Processes in the Delivery of Service Quality. J. Mark. 1988, 52, 35-48. [CrossRef]

22. Tsang, N.K.F.; Lee, L.Y.S.; Wong, A.; Chong, R. THEMEQUAL_Adapting the SERVQUAL Scale to Theme Park Services: A Case of Hong Kong Disneyland. J. Travel Tour. Mark. 2012, 29, 416-429. [CrossRef]

23. Kwak, W.J.; Kim, H.-K. Servant Leadership and Customer Service Quality at Korean Hotels: Multilevel Organizational Citizenship Behavior as a Mediator. Soc. Behav. Pers. Int. J. 2015, 43, 1287-1298. [CrossRef]

24. Lim, S.; Son, D.; Kim, J.; Lee, Y.B.; Song, J.-K.; Choi, S.; Lee, D.J.; Kim, J.H.; Lee, M.; Hyeon, T.; et al. Transparent and Stretchable Interactive Human Machine Interface Based on Patterned Graphene Heterostructures. Adv. Funct. Mater. 2014, 25, 375-383. [CrossRef]

25. Lee, Y.-H.; Wu, J.-Y. The effect of individual differences in the inner and outer states of ICT on engagement in online reading activities and PISA 2009 reading literacy: Exploring the relationship between the old and new reading literacy. Learn. Individ. Differ. 2012, 22, 336-342. [CrossRef]

26. Lee, S.-J.; Lee, W.-N.; Kim, H.; Stout, P.A. A Comparison of Objective Characteristics and User Perception of Web Sites. J. Interact. Advert. 2013, 4, 61-75. [CrossRef]

27. Hoffmann, A.O.; Franken, H.; Broekhuizen, T.L. Customer intention to adopt a fee-based advisory model: An empirical study. In retail banking. Int. J. Bank Mark. 2012, 30, 102-127. [CrossRef]

28. Liu, Y.; Shrum, L.J. What is Interactivity and is it Always Such a Good Thing? Implications of Definition, Person, and Situation for the Influence of Interactivity on Advertising Influences. J. Advert. 2002, 31, 53-64. [CrossRef]

29. Dick, A.S.; Basu, K. Customer Loyalty: Toward an Integrated Conceptual Framework. J. Acad. Mark. Sci. 1994, 22, 99-113. [CrossRef]

30. Fan, L.; Gao, L.; Lou, F.; Liu, X.; Zhao, S.; Mu, H.; Li, Z.; Shi, L.; Wang, L.; Jia, X.; et al. Patients' perceptions of service quality in China: An investigation using the SERVQUAL model. PLoS ONE 2017, 12, e0190123. [CrossRef] [PubMed]

31. Lee, S.M.; Koo, Y.R. A Study on the Key Design Trends of the Company Campuses for Organizational Innovation in a New Era of Sustainability - Focusing on the Recent Cases of Global IT Organizations. J. Korean Soc. Des. Cult. 2017, 23, 427-443. [CrossRef]

32. Lee, H.J.; Lee, U.H.; Lee, G.H. The Impact of University Students' Perceived Service Quality of Mobile Social Commerce on Their Satisfaction and Continued Usage Intentions. J. Consum. Cult. 2017, 20, 234-254. [CrossRef]

33. No, J.H.; Son, J.H.; Kim, J.H. Action Research to Improve Experimental Activities and Interactions in Online Science Class. J. Korean Soc. 2021, 14, 159-172.

34. Hong, E.; Cho, K.; Choi, J. Effects of Anthropomorphic Conversational Interface for Smart Home: An Experimental Study on the Voice and Chatting Interactions. J. HCI Soc. Korea 2017, 12, 15-23. [CrossRef]

35. Aaker, D.A. Managing Brand Equity; The Free Press: New York, NY, USA, 1991.

36. Jacoby, J.; Kyner, D.B. Brand Loyalty Vs. Repeat Purchasing Behavior. J. Mark. Res. 1973, 10, 1-9. [CrossRef]

37. Lee, M.; Ulgado, F.M. Consumer evaluations of fast-food services: A cross-national comparison. J. Serv. Mark. 1997, 11, 39-52. [CrossRef]

38. Venkatesh, V.; Morris, M.G.; Davis, G.B.; Davis, F.D. User Acceptance of Information Technology: Toward a Unified View. MIS Q. 2003, 27, 425-478. [CrossRef]

39. Dautenhahn, K.; Ogden, B.; Quick, T. From embodied to socially embedded agents-Implications for interaction-aware robots Cogn. Syst. Res. 2001, 3, 397-428. [CrossRef]

40. Cho, R.; Im, S.H. AI Chatbot Users' Satisfaction and Intention for Continued Use: Moderating Effects of Chatbot Type and Motivations. Kor. Con. Ass. 2020, 20, 630-640. [CrossRef]

41. Hu, L.T.; Bentler, P.M. Cutoff criteria for fit indexes in covariance structure analysis: Conventional criteria versus new alternatives. Struct. Equ. Model. Multidiscip. J. 1999, 6, 1-55. [CrossRef]

42. Browne, M.W.; Cudeck, R. Alternative ways of assessing model fit. Sociol. Methods Res. 1992, 21, 230-258. [CrossRef]

43. Kim, M.S.; Boo, K.M.; Im, K.D.; Ko, S.B.; Kim, S.B. An Interactive UCC Creation and the Effect Analysis. Sci. Emot. Sensib. 2010, 13, 459-466.

44. Song, M.K.; Yun, H.H. The Effects of Interpersonal Justice and Authenticity on Forgiveness, Sympathy and Revisit Intention in Restaurant's Service Recovery. Culin. Sci. Hosp. Res. 2020, 26, 133-413. [CrossRef] 
45. Lee, H.J.; Cho, C.H.; Lee, S.Y.; Keel, Y.H. A Study on Consumers' Perception of and Use Motivation of Artificial Intelligence(AI) Speaker. Korean Con. 2019, 19, 138-154. [CrossRef]

46. Chen, S.-C.; Lin, C.-P. The impact of customer experience and perceived value on sustainable social relationship in blogs: An empirical study. Technol. Forecast. Soc. Chang. 2015, 96, 40-50. [CrossRef]

47. Turel, O.; Serenko, A.; Bontis, N. User acceptance of hedonic digital artifacts: A theory of consumption values perspective. Inf. Manag. 2010, 47, 53-59. [CrossRef] 